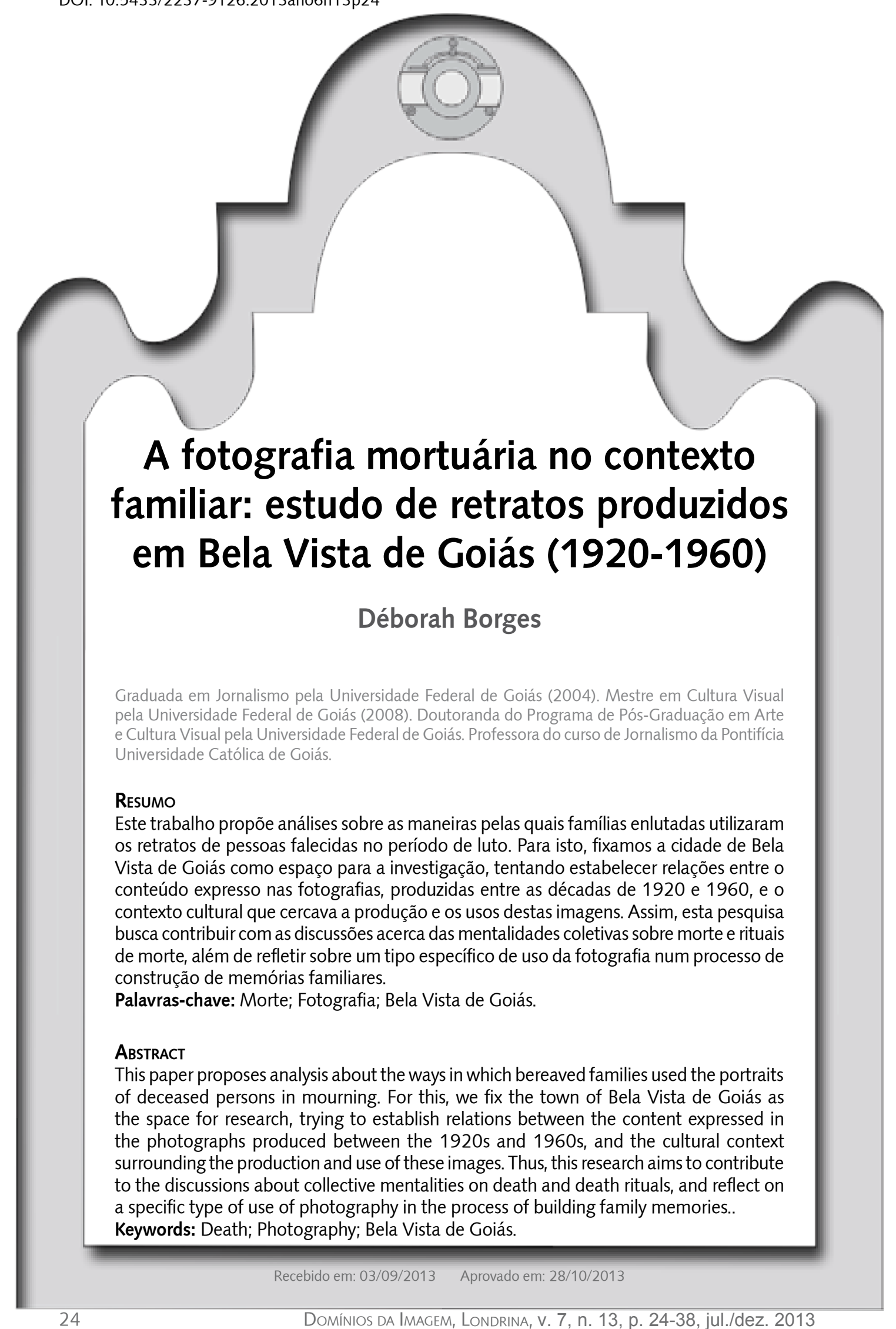

Introdução

Falar sobre a morte é uma tarefa difícil em uma cultura na qual a maioria das pessoas prefere nem mesmo pensar sobre ela. O homem urbano ocidental se sente atemorizado pelo fato de que a morte é certa, definitiva e repleta de mistérios. Numa era de tantos avanços técnicos e científicos, a morte parece ser a única capaz de desafiar a capacidade do ser humano atual de dominar todos os territórios e assuntos. Então, torna-se mais cômodo não pensar sobre ela. Segundo Rodrigues (1983, p. 66),

[...] tudo o que representa o insólito, o estranho, o anormal, o que está à margem das normas, tudo o que é intersticial e ambíguo, tudo o que é anômalo, tudo o que é desestruturado, pré-estruturado e anti-estruturado, tudo o que está a meio caminho entre o que é proximo e predizível e o que é longínquo e está fora de nossas preocupações, tudo o que está em nossa proximidade imediata e fora de nosso controle, é germe de insegurança, inquietação e terror: converte-se imediatamente em fonte de perigo.

A morte e tudo o que se refere a ela é localizado, pela nossa cultura, numa zona intersticial, sobre a qual as estruturas culturais não têm pleno domínio. Isto é resultado de um longo processo que se iniciou no século XVIII. Neste período, segundo Menezes (2004, p. 28), consolida-se "[...] a mudança de paradigma que instituiu a racionalidade anátomo-clínica como fundamento da medicina. [...] A medicina, seu saber e sua instituição tornam-se referências centrais no que se refere a saúde, vida, sofrimento e morte". Desta forma, o doente, o moribundo e a morte passam a ser cada vez mais confinados ao hospital, permanecendo longe do cotidiano imediato das pessoas. A autora aponta ainda que ao longo do século XX "[...] a estrutura de personalidade dos indivíduos é alterada com o esvaziamento dos rituais seculares e um controle individual maior sobre a expressão dos sentimentos face ao sofrimento e à morte" (MENEZES, 2004, p. 35). Enfim, pode-se afirmar que a atitude ocidental contemporânea de repúdio à proximidade com a morte resulta destes dois processos: a medicalização da vida e da morte, sobretudo com a transferência cada vez mais frequente do moribundo para o hospital, e a crescente desvalorização dos rituais, principalmente os religiosos, como meio de gerenciar a morte e o período de luto.

O objeto das análises propostas neste trabalho causa estranheza e repulsa a muitas pessoas na contemporaneidade. Quando se trata da fotografia de um defunto, o homem ocidental contemporâneo muitas vezes não compreende e até mesmo condena quem produz esses retratos. E não só quem pratica, mas também quem estuda a foto mortuária tem sido alvo de críticas na contemporaneidade, segundo Ruby (1995). Como se tais pessoas nutrissem um reprovável gosto para o mórbido.

Percebe-se, desta forma, que atualmente a morte é um assunto mais incômodo até do que o sexo nas culturas ocidentais. De acordo com Maranhão (1986, p. 9), [...] no espaço destas últimas cinco décadas assistimos a um fenômeno curioso na sociedade industrial tema proibido uma coisa inominável. A obscenidade não reside mais nas alusões às coisas referentes ao início da vida, mas sim aos fatos relacionados com o seu fim. 
Desta forma, diversas práticas fúnebres e de luto, assim como tudo o que se relacione ao tema da morte, vêm sendo cada vez mais afastadas do cotidiano do homem ocidenta urbano contemporâneo. Vê-se a morte em filmes, livros, jogos eletrônicos e veículos de comunicação, diariamente. Mas a morte, enquanto fenômeno biológico desencadeador de uma série de manifestações e sentimentos socialmente compartilhados, não se insere no dia-a-dia das pessoas no Ocidente. A morte não o sexo, é o grande tabu contemporâneo. Conforme expõe Maranhão (1986, p. 10),

[...] a permanente popularidade dos filmes de terror e o aparecimento de um novo culto da violência nas produções cinematográficas confirmam esse deslocamento do tabu. A morte, não o sexo, é agora o tabu que violamos - a "pornografia da morte" causanos excitação.

Neste contexto de rejeição da temática da morte, propor uma reflexão sobre a fotografia mortuária não é tarefa fácil. Com o propósito de analisar os sentidos de retratos fúnebres produzidos em Bela Vista de Goiás no período de 1920 a 1960, faço inicialmente uma reflexão sobre o que é a fotografia mortuária e suas tipologias mais comun ao longo do tempo, buscando percebê-la como artefato elaborado socialmente. Em seguida, unindo esse referencial teórico aos relatos fornecidos pelos proprietários das fotografias cedidas para esta pesquisa, busco analisar os sentidos, os usos e as funções da fotografia mortuária no contexto belavistense do período analisado. Assim, espero oferecer uma contribuição à compreensão da relações entre a fotografia e a morte, em especial como a linguagem fotográfica se mostra adequada, no contexto familiar, à necessidade de expressão de uma série de sentimentos relacionados à morte e ao luto.

\section{Fotografia mortuária e memória}

Para Riera (2006) a fotografia mortuária se refere a todos os tipos de fotos realizadas após a morte de alguém, incluindo as que são encomendadas pelos familiares, as que se utilizam nos veículos de comunicação e as imagens forenses, por exemplo. Entretanto, esta pesquisa considera "[...] as imagens post mortem tomadas como recordação familiar do falecido, ou seja, fotografias encomendadas por particulares para sua utilização ou exibição privada, em geral dentro do próprio lar" (RIERA, 2006, s/p., tradução da autora). Trata-se, portanto, de fotografias produzidas com um fim específico e diferente de todos os outros tipos de imagens que representam pessoas mortas. Seu uso se associa ao processo de luto, que é uma experiência vivenciada, sobretudo dentro de um núcleo familiar; daí o fato de ser restrita a um certo número de pessoas a visualização das fotografias dos mortos de uma determinada família.

Ruby (1995) utiliza em seu trabalho o termo mortuary portraits, que pode ser traduzido por retratos mortuários. Isto se deve, em parte, ao fato de que o autor aborda em sua pesquisa outras imagens de mortos além das fotografias. Entretanto, todas elas têm em comum o fato de serem retratos ${ }^{1}$ sejam pinturas, daguerreótipos, fotografias em papel ou porcelana.

A fotografia mortuária é uma prática que teve início quando do advento do daguerreótipo, na Europa, cuja descoberta foi anunciada oficialmente em 1839 (AMAR, 2001). Durante todo o século XIX, fotografa os mortos foi uma atividade desempenhada correntemente pelos fotógrafos na

1 "Representação tangível, em duas ou três dimensões, da fisionomia de uma pessoa" (LEMOS, 1983, p. 49).
Europa e nas Américas, a ponto de muitos deles publicarem anúncios em veículos de comunicação, propagandeando suas habilidades em fazer belos retratos de pessoas falecidas. Mellid (2006) e Riera (2006) afirmam que os retratos mortuários tiveram considerável importância para o próprio desenvolvimento da fotografia, tanto que os defensores da nova técnica faziam referência aos bons resultados obtidos nos retratos de defuntos para exemplificar as qualidades da nova tecnologia.

De fato, segundo Bolloch (2002), o retrato mortuário foi praticado desde o advento da daguerreotipia, até mesmo como oportunidade de aprendizado e aperfeiçoamento da nova técnica pelos artistas da época. Assim, o autor relata que em

14 de outubro de 1839, ou seja, alguns meses após a apresentação à academia de ciências do método desenvolvido por Daguerre e dois meses após a sua divulgação, as Atas entregues à Academia de Ciências fazem exposição da leitura de uma carta assinada pelo doutor Alfred Donné: “Eu tenho a honra de vos enviar as novas imagens Daguerrianas gravadas pelo procedimento cujos primeiros ensaios apresentei à Academia". O autor labora una lista de obras emquestão "Eujá elabora uma lista de abras em questão: "Eu já de uma pessoa mon". Ifelizm a inagem de uma pessoa morta". Infelizmente nenhum (BOLLOCH, 2002, p. 112, traduçado. , p. 112, traduçáo de Carolina Diomara)

Entretanto, por este depoimento percebemos que $\mathrm{o}$ ato de retratar uma pessoa morta pôde ser comunicado abertamente pelo doutor Alfred Donné, sem a preocupação em se tornar alvo de críticas. Isto aponta para o fato de que no século XIX o ato de registrar as feições de um morto era socializado na Europa Ocidental. Além disso, a fala mencionada por Bolloch (2002) demonstra a importância desse tipo de retrato nos primórdios do desenvolvimento da técnica fotográfica.

Na verdade, fazer um belo retrato de um defunto não era uma das atividades mais complicadas dos daguerreotipistas, visto que, como ressalta Mellid (2006, s/p., tradução da autora),

[...] tratavam-se dos melhores modelos nesse momento em que os tempos de exposição dos falecidos favoreceu em alguma mudida dos falecidos favoreceu en alguma medida a proliferaçāo deste tipo de retratos, já que o fotógrafo não tinha que tomar precauçôes disso, tina disso, tisha certa liberdade de manipulação, como se se tratasse de uma natureza morta.

Portanto, havia, de certa forma, considerável liberdade criativa do fotógrafo, que poderia fazer o retrato em algum ambiente dentro da casa do falecido ou mesmo em seu próprio estúdio fotográfico, sem precisar se preocupar muito com os tempos de exposição necessários. Assim, poderiam utilizar-se inúmeros arranjos de luz, poses e diversos atributos a fim de embelezar o morto e a cena.

Além da publicidade feita pelos fotógrafos sobre suas habilidades em retratar defuntos, também era comum que, no século XIX, esses profissionais discutissem em veículos especializados sobre as técnicas para a produção de boas fotografias de mortos. Segundo Ruby (1995, p. 110, tradução da autora), "[...] fotógrafos profissionais eram regularmente solicitados para retratar o morto. Eles anunciavam o serviço em jornais e mantinham discussões profissionais nos seus jornais sobre o melhor meio de realizar a tarefa".

Fotografar os mortos era, pois, uma prática aceita socialmente no século XIX, embora não tenha chegado a constituir uma 
obrigatoriedade entre os ritos mortuários existentes no período. Os familiares poderiam optar por fazer, ou não, retratos de seus mortos. Não há evidências da existência de um dever moral ou religioso desta natureza nas sociedades cristãs ocidentais, como ocorria, por exemplo, com o uso de roupas pretas como marca de luto numa família, comportamento com regras cuja observância deveria ser bastante rígida. Apesar de Riera (2006) afirmar a existência de uma quase "obrigatoriedade" das famílias em faze retratar seus mortos no século XIX, considero mais acertado falar numa grande aceitação social desse tipo de imagem. A popularização dessa prática provavelmente fez com que houvesse certa expectativa das pessoas em encomendarem fotografias de seus entes queridos mortos, não propriamente em cumprimento a uma exigência sociocultural mas, antes, pelo reconhecimento de um certo valor em perpetuar uma última imagem do morto.

costume de fotografar os mortos persistiu com maior força na cultura cristã ocidental até meados do século XX. Segundo Koury (2001, p. 107),

[...] a fotografia mortuária surge logo após o aparecimento da fotografia como arte e como técnica de registro e fixação de um presente passado específico. Sua popularização, contudo, vai se dar entre os anos de 1920 1950, quando é utilizada por várias camadas da população.

Entretanto, embora o hábito de fotografa os mortos tenha se mantido na passagem do século XIX para o XX, Ruby $(1995$, p. 55 tradução da autora) aponta uma diferença na prática desse tipo de representação nos dois séculos. Segundo o autor, "[...] no século dezenove os fotógrafos anunciavam e discutiam abertamente a prática".
Já no século $X X$, embora a fotografia mortuária tenha continuado a ser praticada os profissionais já não anunciavam o serviço e tampouco discutiam técnicas específicas para a produção destes retratos. Ruby (1995) atribui este silêncio sobre a fotografia mortuária na primeira metade do século $X X$ ao fato de que a existência da prática de fotografar os mortos se tornou tão conhecida e aceita socialmente que era desnecessário anunciar tais serviços ou discutir sobre sua produção publicamente, uma vez que já se encontravam estabelecidos certos modelos para a produção destas imagens.

Com relação às motivações para a realização de fotos mortuárias e seus usos, podemos dizer que tanto no século XIX quanto no XX, tanto na Europa quanto nas Américas, não são fatores morais, religiosos ou sociais os principais justificadores desta prática. A imagem de um morto particularizado é concebida e utilizada, sobretudo, dentro de um contexto de vivência da dor pela perda de um ente querido. Para Ruby (1995), não há dúvidas de que as pessoas encomendavam retratos assim porque elas sentiam a necessidade de uma última lembrança visual de seus parentes e amigos. É importante destacar que esta necessidade se manifestava não apenas como um desejo de reter apenas os traços fisionômicos do ente querido falecido, mas, mais do que isso, ter um registro permanente do morto enquanto morto. Nas palavras de Koury (2001, p. 68), a foto mortuária "[...] visa deter os traços da morte e da deterioração posterior do cadáver, amenizando a dor dos que ficam, quando da evocação do morto através do registro".

O uso da fotografia mortuária, então, estava relacionado ao processo de vivência da morte, na medida em que permitia aos familiares recordarem os acontecimentos relacionados a essa passagem e aos ritos fúnebres realizados na ocasião. Esta função do retrato mortuário permanece nos dias atuais, conforme Ruby (1995) e Koury (2001), embora num outro contexto de produção e consumo, diferente do que existia no século XIX e na primeira metade do século XX.

Além de sua importância no processo de luto, destaco também uma função de comunicação desempenhada pela fotografia mortuária que, segundo Ruby, ainda é verificada nos círculos sociais onde persiste a prática de retratar os mortos. Há vários casos em que a comunicação da morte de alguém foi feita por meio de retratos fotográficos do morto enviados a parentes que não puderam comparecer ao velório. Conforme expressa Ruby (1995, p. 161), "[...] a fotografia foi tomada como um substituto para a experiência - obviamente uma das mais básicas funções da fotografia".

$\mathrm{Na}$ complexa relação que as pessoas tentam estabelecer com seus mortos, portanto, a fotografia, enquanto objeto de rememoração, tem uma considerável importância, segundo Ruby. Entretanto, o mesmo autor chama a atenção para a existência de poucos estudos sobre os usos da fotografia, de modo geral, nos processos de luto. Quanto à foto mortuária, particularmente, ao menos no século XIX e na primeira metade do século $X X$, sua importância e seus usos parecem ter sido socializados de forma harmoniosa tanto na Europa quanto nas Américas. A prática de fotografar um morto e a posterior contemplação desse retrato como meio de elaborar a perda e reverenciar a memória do falecido não eram alvos de críticas. No século XIX, ainda que os usos e a exibição das fotos mortuárias nem sempre se estendessem para fora do círculo familiar, a prática era conhecida e aceita por fotógrafos e demais

\section{atores sociais.}

Ver o morto no contexto mesmo de sua morte, seja para lembrar de uma experiência vivida ou para formular outro tipo de experiência de dor e pesar pela morte de um parente ou amigo: seja qual for o uso que a fotografia mortuária possa ter tido, parece haver uma forte ligação entre a prática de retratar os mortos e a construção e a manutenção de memórias. A relação da fotografia com a lembrança e a memória, em especial a de família, não se restringe aos retratos mortuários. Entretanto, como o ato de recordar, de (re)construir memórias é inerente ao processo de vivência da dor da perda durante o período de luto, a preservação da memória é uma das razões mais fundamentais para se fazer a fotografia de um defunto. Para Sontag (2003, p. 96),

[...] recordar é um ato ético, tem um valor ético em si mesmo e por si mesmo. A memória é, de forma dolorosa, a única relação que podemos ter com os mortos. Portanto a crença de que recordar constitui um ato ético é profunda em nossa natureza de seres humanos, pois sabemos que vamos morrer e ficamos de luto por aqueles que, no curso normal da vida, por aqueles que, no curso normal da vida, morrem antes de nós - avós, pais, professores parecem andar juntas.

Ora, segundo o raciocínio da autora, podemos perceber o quanto é difícil e também necessária a relação dos vivos com seus mortos. Nenhum grupo humano mantém indiferença no tratamento dispensado aos defuntos. Bayard (1996, p. 43) expressa a importância deste comportamento afirmando que "[...] o homem é o único animal que acende fogo e enterra mortos". O fato de nutrir sentimentos em relação a seres que deixaram de existir neste mundo diferencia o homem dos outros animais. E a maneira básica pela qual essa relação entre 
vivos e mortos se processa é pela memória. Alimentar esta memória é a função primordia de construções tumulares, monumentos funerários e da fotografia mortuária, dentre outros objetos confeccionados no contexto de vivência do sofrimento pela morte do ser amado. $E$, sendo a recordação um ato ético, segundo Sontag (2003), ao edificar um túmulo ou tirar uma foto de seu morto, o ser humano expressa determinados valores morais, religiosos e culturais que são socialmente compartilhados.

\section{Tipologias}

Segundo Jay Ruby (1995), é possíve identificar três estilos de representação do defunto nos retratos fotográficos mortuários do século XIX. Segundo o autor, "[...] dois tipos foram elaborados para 'negar a morte', ou seja, para simular que o falecido não estava morto, enquanto uma terceira variação retrata o falecido com os enlutados" (1995, p. 63 , tradução da autora). No primeiro estilo, denominado por Ruby como "O Último Sono", representa-se o morto como se estivesse, na verdade, repousando. A figura 1 mostra um exemplo desta tipologia. Nela percebemos uma intenção de registrar a criança morta como se estivesse repousando. A pequena defunta foi colocada numa cama enfeitada por um rico enxoval branco, mesma cor das vestes da menina. $O$ esmero com que foi feito o arranjo da cena chama a atenção. O lençol que cobre parte do corpo da criança foi cuidadosamente esticado; as flores foram distribuídas de maneira harmoniosa ao redo da pequena morta. Entretanto, esta imagem possibilita uma interpretação de que a retratada esteja morta, e não simplesmente repousando. As mãos da menina estão postas em pose de oração, com os dedos entrelaçados, de onde pende um rosário. Ora, é perfeitamente possível a compreensão de que esta criança está morta, uma vez que a

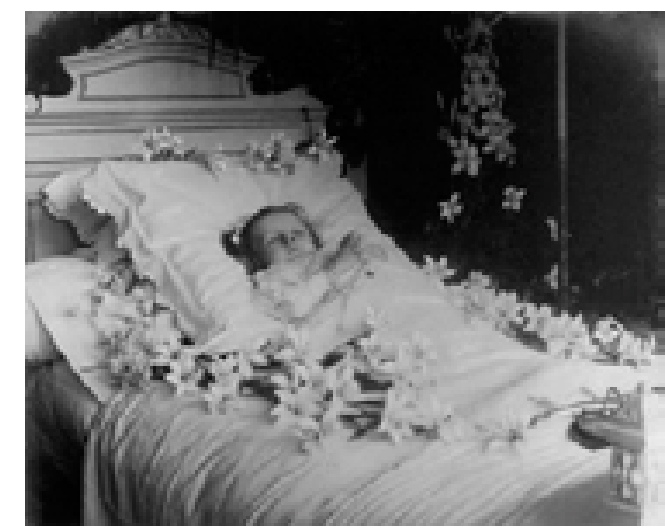

produção da cena evidencia isto pela presença de elementos que aludem aos ritos funerários da época, tais como as flores e o rosário. XIX. In: http://www.thanatos.net, acesso em 20 jul. 2007.

Assim, é possível destacar uma ambiguidade com relação à pose denominada "Último Sono". Aparentemente, havia um desejo de retratar o morto como se não estivesse morto, mas dormindo. Entretanto, o enlutado que fazia uso de uma imagem assim tinha consciência de que o retratado estava, de fato, morto. Percebemos, aí, a importância da bela aparência do defunto e da associação da morte com o sono dentro da mentalidade ocidental sobre a morte no século XIX. Ora, estas imagens cumpriam um papel no processo de elaboração do luto e, neste sentido, fazia-se necessário cuidar para que o último registro visual da pessoa morta reforçasse nos sobreviventes a crença de que seu ente querido desfrutava de uma boa morte.

Vale lembrar que a fotografia mortuária, de modo geral, e especialmente a pose do "Último Sono", foi prática comum em países predominantemente protestantes, caso dos Estados Unidos (RUBY, 1995). Em geral, associa-se a noção da boa morte com a doutrina católica, mas este é um conceito de alguma forma desenvolvido em diversas culturas. Se a doutrina protestante não permitia as figuras dos santos e da Virgem quanto mais contemplá-las como exemplos de boa morte! - com o advento da fotografia os retratos mortuários serão amplamente utilizados entre fiéis desta vertente religiosa tanto na Europa quanto na América do Norte.

A ideia da morte como sono foi mantida entre os protestantes como um repouso entre a morte individual e a ressurreição. Segundo Silva (1993, p. 143)

[...] de acordo com o espírito reformado, só existiam dois lugares para as almas após a morte: o Paraíso, onde repousavam as almas dos justos e não precisavam da intervenção dos vivos pois estavam ao lado de Deus, e o Inferno, de onde as almas condenadas jamais sairiam. Desta maneira, as almas não retornavam de onde estavam como também não adiantavam orações ou sufrágios especiais para os mortos.

Sendo assim, podemos supor que a boa aparência do morto na foto seria uma necessidade ainda maior entre os protestantes do que entre os católicos. Ora, se não há nada que os sobreviventes possam fazer para contribuir com a salvação da alma de seus entes queridos, então não é de se estranhar que os protestantes necessitassem de algum tipo de garantia de que seus parentes e amigos tiveram uma boa morte, digna do reino dos céus.

Talvez ainda mais ambíguas possam parecer as fotografias mortuárias do segundo estilo definido por Ruby (1995), denominado "Vivo, embora morto". Nestas imagens pretende-se eternizar a figura do morto como se, na verdade, estivesse vivo; não dormindo, mas posando para a objetiva como uma

\section{pessoa viva.}

Por que isto acontecia? Não é fácil encontrar uma resposta exata para esta questão. Afinal, como bem expressa Riedl (2002, p. 171), " [...] para o ato de fotografar os mortos não há necessariamente uma relação causal entre origens e efeitos". Entretanto, podemos supor uma explicação para pelo menos parte dos casos de fotografias do estilo "Vivo, embora Morto". Em diversas situações o que ocorria era que o retratado morria sem nunca ter tirado uma fotografia em vida. Assim, a foto mortuária acabava sendo o único registro visual disponível para os familiares. Daí, talvez, a necessidade de utilizar uma série de estratagemas para fazer com que o defunto parecesse estar vivo nestas fotografias, como, por exemplo, utilizar uma colherinha de café para abrir os olhos do morto e, depois, recolocá-los corretamente na órbita ocular (RIERA, 2006). Em outras situações, como ocorre na figura 2, podia-se também pintar os olhos abertos na fotografia após a fixação da imagem, ou apenas efetuar retoques em retratos onde os olhos do defunto já estivessem abertos.

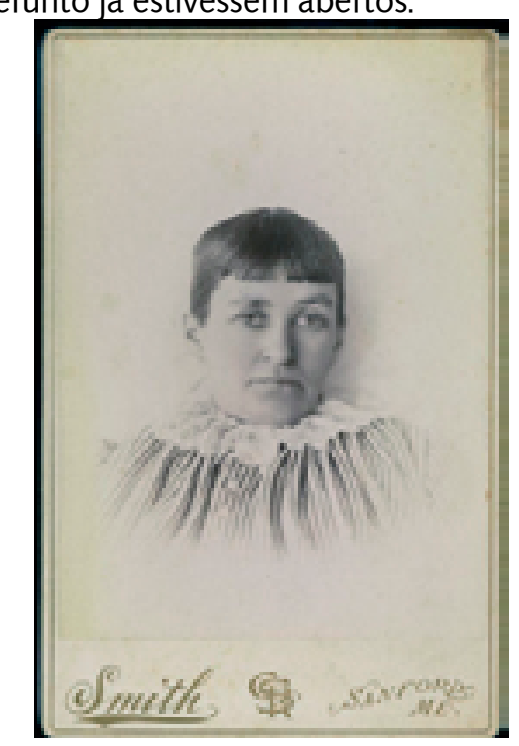

Fig. 2: Fotografia mortuária do tipo Vivo, embora morto. Século XIX. 
Além disso, podia-se colocar a pessoa morta sentada, com as pernas cruzadas, segurando algum objeto, ou fazer com que ela permanecesse de pé apoiada em outras pessoas ou em outros tipos de suportes mais elaborados (esta última pose é mais rara) Enfim, percebemos que

[...] costumava-se dar completa liberdade à pessoa encarregada de tomar a imagem para vestir e dispor o corpo como considerasse propriado. Muitos dos fotograns daquela epoca se converteram em autênticos especialistas da maquiagem, chegando obter-se resultados muito espetaculares em (RIERA, 2006, tradução da autora)

Estes dois primeiros tipos - "O Último Sono" e "Vivo, embora Morto" - ocorreram com mais frequência no século XIX, conforme Ruby (1995). Já a terceira categoria de fotos mortuárias, que retrata o morto como morto, surge concomitantemente às outras persiste como principal modelo até meados do século $X X$. Nestas imagens, encontramse elementos que permitem a interpretação exata de que o retratado está, de fato, morto. Na figura 3, por exemplo, vemos uma criança morta dentro de um caixão branco, mesma cor de suas vestes. A foto foi feita no cemitério onde a menina seria enterrada em seguida: no segundo plano, erguem-se algumas construções tumulares, e logo atrás do caixão parece haver uma cova aberta. Ora, neste exemplo há elementos mais do que suficientes para afirmar que a criança retratada está morta.

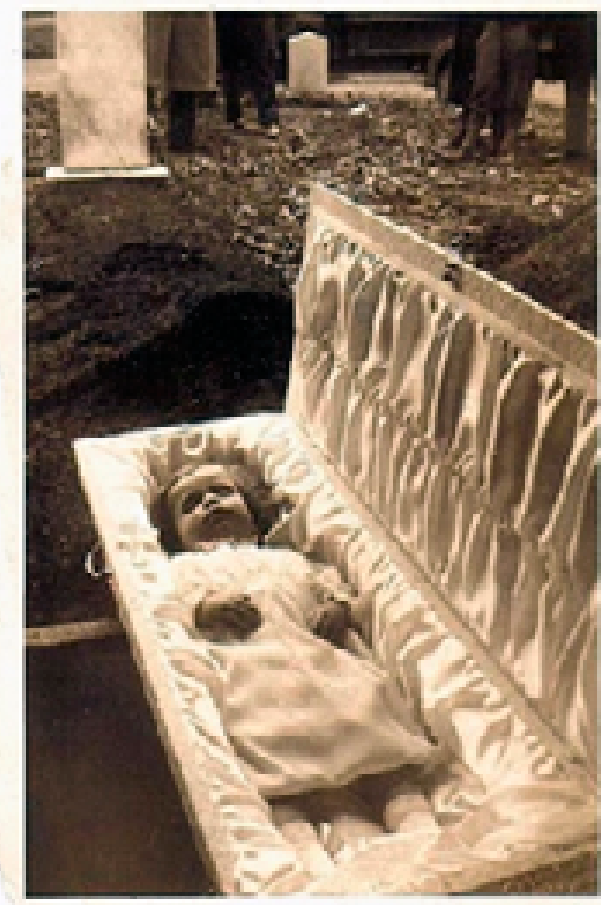

Fig. 3: Fotografia mortuária do morto como morto Século XIX. In: http://www.thanatos.net, acesso em 20 jul. de 2007.

Segundo Koury (2001), a fotografia mortuária também teria importância como meio de referenciar socialmente o morto ${ }^{2}$ Assim, um dos propósitos da prática de retratar um defunto seria.

2 Neste sentido, podemos destacar também a prática de fazer máscaras mortuárias do defunto, que foi exercida com bastante frequência até o século XIX, sobretudo para pessoas ilustres Segundo Raynaud (2002, p. 22 e 23, tradução de Carolina Diomara) “[ . ] a máscara mor Carolina Dis uma evidente manifestação da obsessão macabra que assombra os homens do fim da Idade Média. [...] Artifício dos funerais do século $\mathrm{XV}$ que celebravam, pela pompa estendida, a glória terrestre do defunto, oferecia outra forma de imortalidade a este último permitindo aos artistas compor retratos póstumos. [...] Por trás da mascara perfila-se assim un fenômeno essencial: a afirmação do indivíduo". Exemplos de máscaras mortuárias podem ser encontrados em Normand-Romain (1995).
[...] fixar para a eternidade o prestígio do morto e dos seus familiares que ficam, para a comunidade à qual pertencia. [...] Fotografias que consolidavam não apenas o prestígio social, político e econômico do morto, mas a sua continuidade através da família (KOURY, 2001, p. 85-86)

Assim, em diversos casos, parece haver um interesse em registrar a opulência dos funerais, captando na fotografia a riqueza das vestes e dos adereços de mortos e vivos, a exuberância dos adornos utilizados na decoração da cena e a presença de pessoas ilustres ao velório, como estratégia de perpetuação de uma memória do morto como integrante de um determinado grupo social.

Fotografias mortuárias de Bela Vista de Goiás

As fotografias mortuárias, frequentemente, são inseridas no contexto de outros ritos fúnebres compartilhados pelos integrantes de determinadas sociedades. Em Bela Vista de Goiás, constataremos a presença de costumes como o uso de roupas pretas entre os familiares enlutados, 0 anúncio da morte por meio de badaladas do sino da Igreja - cujas variações informavam, também, se se tratava de criança, adulto, homem ou mulher -, as missas de corpo presente e as posteriores, de sétimo dia, de um mês e um ano de falecimento, conforme serve de testemunho o relato de Maria Adélia Mendonça Arantes (2007). Trata-se de rituais identificados também em outras regiões do país.

O que interessa ressaltar, aqui, é o fato de que em Bela Vista de Goiás os ritos mortuários contavam com grande participação de outras pessoas, além do núcleo familiar. Isto demonstra o quão socialmente aceitos, e té mesmo obrigatórios, em certa medida, eram essas celebrações. Um único relato exemplifica bem o quanto a sociedade belavistense demonstrava solidariedade para com a família enlutada, por meio do cumprimento dos costumes mortuários. Maria Adélia, ao relembrar a morte de seu filho Domingos, na madrugada de 21 de maio de 1941, vítima de difteria, conta o seguinte:

[...] todos se comoveram com esta morte. Os parentes, os amigos, os vizinhos. [...] Naquele 作 erta porta com todos os alunos uniformizados, para anos e sete meses (ARANTES, 2007, p. 344).

Percebemos, assim, um tipo de relação com a morte bastante diferente da que se delineia na atualidade, conforme exposto, com uma crescente medicalização da morte uma quase ocultação do cadáver durante os ritos finais ${ }^{3}$.

Fig. 4: Fotografia mortuária do morto como morto. ente 1945. Acervo particular - Nair Alves Teles.

3 Cabe ressaltar que esse processo não tem ocorrido uniformemente em todos os lugares. Em Bela Vista mesmo, até hoje, há uma cultura de solidariedade para com as famílias enlutadas e a permanência de certos ritos, ainda que com algumas modificações. Se antes o anúncio da morte era feito pelo dobrar de sinos da greja e pelo s mesma me lembro de falecimentos anunciados desta forma, quando eu era criança -, com o crescimento da cidade houve a necessidade de realizar essa comunicação por meio de carros de som que percorrem diversos bairros. Além disso, se já não é obrigatório o uso de roupas pretas em sinal de luto, ao menos as visitas às famílias que perderam um de seus membros ainda são praticadas, assim como as missas de sétimo dia, um mês e um ano de falecimento, entre os belavistenses católicos. 


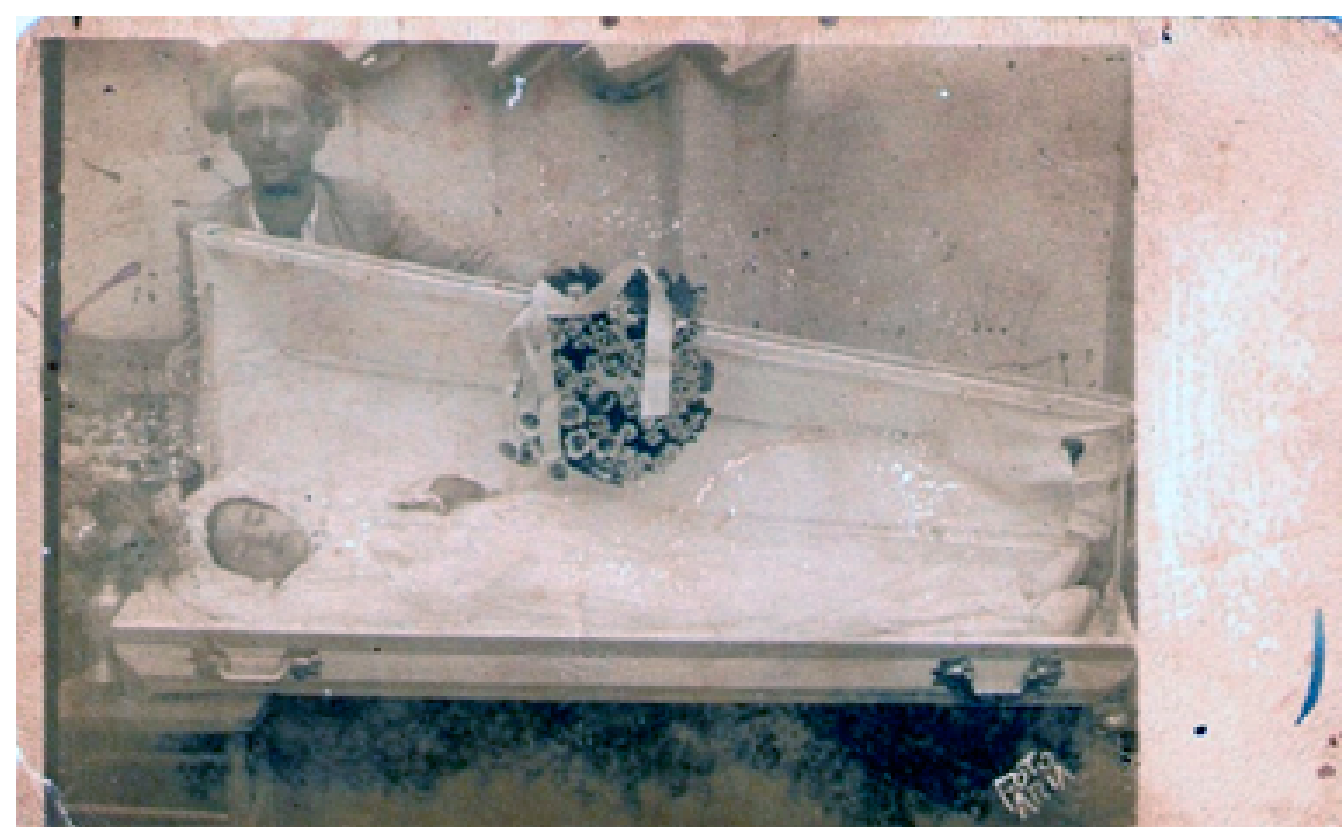

A população belavistense da primeira metade do século XX, aliás, diversas veze não contava com serviço médico nem mesmo para satisfazer suas necessidades mais imediatas, quanto mais para cuidar do moribundos. A morte em casa era bastante comum, conforme se percebe pelos vários relatos de Maria Adélia (2007) sobre mortes ocorridas em seu círculo familiar e de amizades. Uma das fotografias mortuárias localizadas no município, acompanhada pelo relato de sua proprietária demonstra bem esta carência de serviços médicos, e como isso também acabava interferindo na própria mentalidade sobre saúde, doença e morte entre os belavistenses. Trata-se da figura 4 na qual vemos o retrato mortuário de uma moça falecida por volta do ano de 1945 com 15 anos de idade, aproximadamente. $A$ defunta está vestida com uma túnica branca, tendo uma espécie de touca na cabeça, seu corpo foi disposto dentro de um caixão branco ornamentado com um arranjo de flores brancas. O caixão está apoiado sobre duas cadeiras e atrás dele há um homem vestido com um traje mais sóbrio - parece ser um terno, mas sem gravata. No canto fotógrafo, Antônio Faria. A foto não me diz muito mais do que isso.

Entretanto, o relato da proprietária da foto, Dona Nair Alves Teles (2006) permitenos avançar um pouco além na investigação proposta. A fotografada era sua irmã, e o retrato foi feito a pedido do senhor que está junto ao caixão; ele era primo da morta e insistiu para fazer a foto, como meio de guardar uma última recordação da moça. Entretanto, foi ao questionar sobre a causa da morte da menina que a proprietária da imagem forneceu uma informação bastante importante sobre o que os belavistenses da época pensavam sobre saúde e morte: Dona Nair disse que sua irmã havia falecido, muito provavelmente, "[...] por ter se molhado na água fria de um rio durante o período menstrual". Percebe-se aí, que havia limitações no que diz respeito à medicalização da vida dos habitantes do serviços médicos, nem sempre esse socorro inferior direito encontra-se a assinatura do município da época: apesar de recorrerem aos era suficiente para impedir ou mesmo explicar as causas da morte de alguém, como foi o caso da moça da figura 4. Entrecruzavamse, no cotidiano das famílias belavistenses, orientações de origem médica, religiosa , até mesmo, mágica, que serviam para cuidar da saúde de todos os membros da família. Embora não seja o objetivo deste trabalho explorar o imaginário sobre saúde e doença, vale ressaltar que crenças como a manifestada por Dona Nair não surgiam aleatoriamente, mas na maioria das vezes apoiavam-se sobre algum tipo de constatação empírica, por mais precária que fosse.

Para finalizar este artigo, analiso duas fotografias que são muito ricas em informações não apenas sobre a mentalidade da morte em Bela Vista na primeira metade do século $X X$, mas também sobre o imaginário coletivo acerca da fotografia e sua relação com os mortos. Na figura 5 vemos a foto mortuária de uma senhora coberta com um tipo de manto, disposta sobre um banco forrado com tecidos brancos. A cabeça da defunta está apoiada sobre um travesseiro também branco, e seus longos cabelos negros foram cuidadosamente penteados e dispostos sobre seu busto. Ao fundo, sobre algum móvel, há alguns vasos com flores, e na parede, um crucifixo. A foto está bastante deteriorada, e apresenta uma enorme mancha negra na porção superior, mais à esquerda da imagem.

A proprietária da fotografia é Dona Messias Ferreira Prego, e a retratada era sua mãe. Ela faleceu no dia 13 de abril de 1936, vítima de um Acidente Vascular-Cerebral, ou derrame, como se conhece popularmente e como a própria Dona Messias (2006) denomina a enfermidade que acometeu sua mãe. Mas o relato da proprietária traz outra informação importante: os familiares da morta atribuíam a presença da mancha negra na imagem ao fato de que a falecida não gostava de fotografias, e jamais se deixou fotografar em vida. Assim, quando Adelino Roque, fotógrafo que fez a foto, revelou o negativo e ampliou o retrato, todos consideraram que se tratava de um sinal de que a morta não havia ficado satisfeita com a desobediência de sua família, que havia contrariado sua vontade de nunca ser fotografada.

ig. 5: Fotografia mortuária do morto como morto. Adelino Roque. 13/04/1936. Acervo particular - Messias Eerreira Prego.

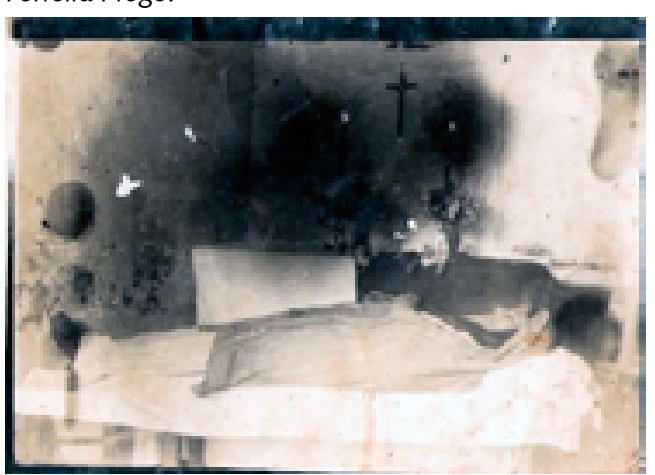

$\mathrm{Na}$ figura 6 temos outro exemplo interessante, ainda nesta relação entre os mortos e a fotografia, a qual integrava de alguma maneira o imaginário coletivo belavistense. Na imagem vemos o retrato de um casal e, centralizada na foto, atravessando-a na horizontal, a foto mortuária de uma mulher. Esta outra imagem se sobrepõe à primeira, e sua transparência deixa entrever aspectos do homem e da mulher retratados. Esta imagem foi reproduzida a partir de um exemplar de propriedade do Senhor Daniel Vieira, mas outra cópia também foi localizada na residência de Antônio Faria, que foi o autor da foto. Trata-se de uma imagem cuja história é repetida há décadas entre os belavistenses: o homem da foto teria matado sua esposa para poder se apoderar de sua herança e casar-se com sua amante, no caso, a mulher retratada a seu lado. Mas, no dia em que se 
fizeram retratar juntos, após o casamento, a morta aparece na foto, e seu braço esquerdo parece enlaçar a mulher, como se quisesse enforcá-la. Perturbado, o homem procura a polícia e confessa o crime, informando inclusive o local onde havia enterrado o corpo de sua esposa. Fig. 6: Sobreposição de fotografias. Antônio Faria

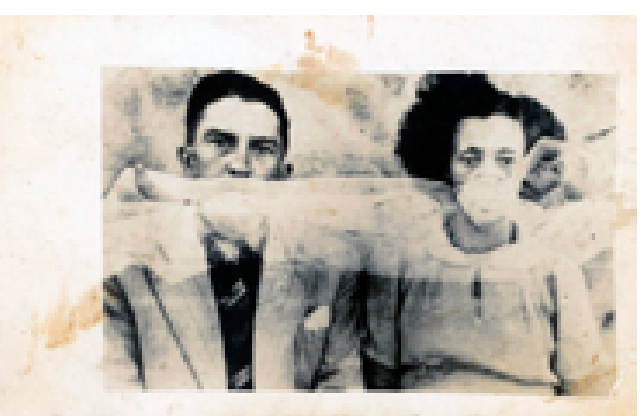

Há, nessas duas histórias, vários aspectos a se considerar. Primeiro, que os erros no momento da tomada da foto, da revelação do negativo e ampliação das cópias em papel eram comuns naquela época, po motivos diversos: má qualidade do materia empregado, falhas no momento da tomada da foto, descuido no manuseio de equipamentos e substâncias, etc. Na própria residência de Antônio Faria foram encontrados outros exemplos semelhantes à figura 6 , onde parece ter havido, na verdade, uma sobreposição de negativos, ou a impressão de duas fotografias num mesmo negativo.

Por outro lado, é interessante observar que no imaginário coletivo belavistense, tanto figura 5 quanto a figura 6 acabaram ganhando outras interpretações, independentes das questões técnicas da fotografia, mais ligadas a histórias vividas pelos retratados, contadas e recontadas, porventura distorcidas. Como bem expõe Kossoy $(2005$, p. 45)

[...] as fantasias da imaginação individual do imaginário coletivo adquirem contornos nítidos e formas concretas por meio do chamado testemunho fotográfico. Se, por um lado, o signo é produto de uma construção invenção, por outro, a interpretação, não raro, desliza entre a realidade e a ficção. Tratam-se (...) de processos de construção de realidades, processos esses que sempre existiram.

Ora, se a interpretação de uma fotografia implica em construir realidades estabelecendo ligações entre o que está explícito na imagem e o que se conhece de seu contexto de produção e uso, das histórias dos retratados, das informações prévias sobre os referentes imagéticos, então constatamos que foi exatamente o que fez a população belavistense nos dois últimos casos analisados: criou realidades histórias, a partir do testemunho propiciado por estas fotografias. Realidade e ficção se misturam de tal maneira nesses casos que, no fim das contas, resta-nos apenas verifica que, definitivamente, dentro do imaginário coletivo belavistense da primeira metade do século XX, a fotografia era um valioso campo de comunicação entre vivos e mortos ademais, de transmissão dessas realidades, por meio da memória, para as gerações futuras.

\section{Considerações Finais}

Para compreender a prática de retrata pessoas mortas, e os usos dessas imagens no contexto da sociedade belavistense entre as décadas de 1920 e 1960, transitamos entre diferentes esferas, daquilo que identificamos como partes de uma memória coletiva sobre a morte até as lembranças mais pessoais fornecidas pelos informantes que cederam alguns de seus retratos de família para a pesquisa. Com isto, conseguimos discutir alguns pontos importantes sobre os processos que permitiam a construção dessas representações no contexto estudado, o qual, como vimos, era marcado pela religiosidade cristã e por um tipo de sociedade onde havia intensa participação de todos os membros nas diferentes comemorações públicas, o que inclui os ritos funerários. Posso dizer que, nesta pesquisa, procurei fazer uma

[...] "desmontagem" do processo de construção que teve o fotógrafo ao elaborar uma foto pelo eventual uso ou aplicação que essa imagem teve por terceiros e, finalmente, pelas "leituras" que dela fazem os receptores ao longo do tempo. Nessas várias etapas da trajetoria da imagem, ela foi objeto de uma sucessão de construções mentais interpretativas por parte dos receptores, os quais Ihe atribuíram determinados significados, conforme a ideologia de cada momento. (KOSSOY, 2005, p. 41)

Assim, em Bela Vista de Goiás pudemos verificar que concorriam, para o ato de fotografar um morto, tanto motivações pessoais dos familiares enlutados quanto fatores sociais, uma vez que o retrato fúnebre consistia em prática corrente nesta sociedade Tecendo relações entre os diversos sujeitos envolvidos na prática de retratar os mortos pela fotografia, buscando identificar seus interesses, creio que pudemos contribuir para uma compreensão da fotografia mortuária, em geral, apesar de termos nos limitado a uma cidade tão pequena, e a um número relativamente reduzido de imagens. Mas, como bem expressa Halbwachs (2004, p 56), "[...] um estado pessoal revela assim a complexidade da combinação de onde saiu". Podemos considerar, neste caso, que a investigação da prática da foto mortuária em Bela Vista, por meio dos casos selecionados, revela a complexidade de uma cultura ocidental na qual o imaginário coletivo cristão sobre a morte é visível nas formas de representação fotográfica de pessoas mortas.

\section{Referências Bibliográficas}

AMAR, Pierre-Jean. História da Fotografia. Tradução de Vitor Silva. Lisboa, Portugal: Edições 70, 2001

ARANTES, Maria Adélia Mendonça. Terra Aranca, terra vermelha. Rio de Janeiro: Edições Galo Branco, 2007.

BAYARD, Jean-Pierre. Sentido oculto dos ritos mortuários: morrer é morrer? São Paulo: Paulus, 1996.

BOLLOCH, Joëlle. Photographie après décès: pratique, usages et functions. In: Le dernier Portrait. Musée d'Orsay, Paris: Réunion des Musées Nationaux, 2002

HALBWACHS, Maurice. A memória coletiva. São Paulo: Centauro, 2004.

KOSSOY, Boris. Fotografia e memória: reconstituição por meio da fotografia. In: SAMAIN, Etienne (Org.). O fotográfico. São Paulo: Editora Hucitec/Editora Senac São Paulo, 2005

KOURY, Mauro Guilherme Pinheiro (Org.). Você fotografa os seus mortos?. In: Imagem e memória - ensaios em Antropologia Visual. Rio de Janeiro: Garamond, 2001.

LEMOS, Carlos A. C. Retratos quase inocentes. São Paulo: Nobel, 1983.

MARANHÃO, José Luiz de Souza. O que é morte. São Paulo: Brasiliense, 1986. 
MELLID, Marisol Romo. Fotografiar a los muertos. 2006. Disponível em http://www. antecamara.com.mx/nuevo/modules.php?o $p=$ modload\&name $=$ PagEd\&file $=$ index\& printerfriendly $=1 \&$ page_id $=706$. Acesso em: 20 jun. 2013.

MENEZES, Rachel Aisengart. Em busca da boa morte: antropologia dos cuidados paliativos. Rio de Janeiro: Garamond: Fiocruz, 2004.

NORMAND-ROMAIN, Antoinette. Mémoire de Marbre: la sculpture funéraire en France (1804-1914). Paris: Bibliothèque histoique de la Ville de Paris, 1995.

PREGO, Messias Ferreira. Depoimento. Entrevista concedida à autora. Bela Vista de Goiás, mar. 2006.

RAYNAUD, Clémence. Du cortège funèbre au portrait posthume: fonctions et enjeux du masque mortuaire à la fin du Moyen Age. In: Le dernier Portrait. Musée d'Orsay, Paris: Réunion des Musées Nationaux, 2002.

RIEDL, Titus. Últimas Lembranças. Retratos da morte, no Cariri, região do Nordeste Brasileiro. São Paulo: Annablume, Fortaleza: Secult, 2002.

RIERA, Alberto. Introducción a la fotografia post mortem. 2006. Disponível em http:// www.caborian.com/content/view/574/142/. Acesso em: 20 jun. 2013.

RODRIGUES, José Carlos. Tabu da morte. Rio de Janeiro: Achiamé, 1983.

RUBY, Jay. Secure the shadow: death and photography in América. USA: The MIT Press, 1995.
SILVA, Eliane Moura. Vida e Morte: o homem no labirinto da eternidade. 1993. $247 \mathrm{f}$. Tese (Doutorado em História) - Instituto de Filosofia e Ciências Humanas da Universidade Estadual de Campinas, Campinas. 1993.

SONTAG, Susan. Diante da dor dos outros. São Paulo: Companhia das Letras, 2003.

TELES, Nair Alves. Depoimento. Entrevista concedida à autora. Bela Vista de Goiás, jun. 2006. 